\title{
Flutamide-Leuprolide Regimen
}

National Cancer Institute

\section{Source}

National Cancer Institute. Flutamide-Leuprolide Regimen. NCI Thesaurus. Code C63790.

A form of combined androgen blockade consisting of flutamide and leuprolide used to treat metastatic prostate cancer. This approach has been widely replaced by the use of either surgical (orchiectomy) or medical (LHRH agonist) castration. 